\title{
Reappraising Burnout Syndrome in Healthcare under Sars-Cov-2 Pandemic
}

\author{
Luis Madeira LDA ${ }^{1-3, \#}$, Mariana Heloísa Narciso 2,\#,*, and Maria João Heitor \\ ${ }^{1}$ Conselho Nacional de Ética para as Ciências da Vida, Portugal \\ ${ }^{2}$ Faculdade de Medicina, Universidade de Lisboa, Lisboa, Portugal \\ ${ }^{3}$ Sociedade Portuguesa de Psiquiatria e Saúde Mental, Portugal \\ ${ }^{4}$ Departamento de Psiquiatria e Saúde Mental, Hospital Beatriz Ângelo, Loures, Portugal \\ "Equal contributions
}

*Corresponding author: Luis Madeira LDA, Conselho Nacional de Ética para as Ciências da Vida, Portugal, E-mail: luismadeiramd@gmail.com

Received: 15 Jun, 2021 | Accepted: 28 Jul, 2021 | Published: 05 Aug, 2021

Citation: Luis Madeira LDA, Narciso MH, Heitor MJ (2021) Reappraising Burnout Syndrome in Healthcare under Sars-Cov-2 Pandemic. J Psychiatry Ment Health 6(2): dx.doi.org/10.16966/2474-7769.143

Copyright: (C) 2021 Luis Madeira LDA. This is an open-access article distributed under the terms of the Creative Commons Attribution License, which permits unrestricted use, distribution, and reproduction in any medium, provided the original author and source are credited.

\section{Abstract}

Background: Burnout Syndrome consists of a set of physical and psychological symptoms, resulting from an excessive workload and can be divided in three main dimensions: Emotional Exhaustion, Depersonalization and Lack of Personal Achievement at Work. It is a prevalent and extremely relevant health problem, affecting over half the health professionals.

Methods: A selective review of the literature on approaches used by healthcare institutions forprevention and intervention in Burnout Syndrome was performed using PubMed database during February 2020. The searches were conducted with the following descriptors: [(BurnoutSyndrome) and (Healthcare professionals)], [(Burnout Syndrome) and (Physicians)], [(BurnoutSyndrome) and (Nurses)], [(Burnout) and (Prevention)], [(Burnout) and (Intervention)] and [(Medical Burnout) and (Prevention)].

Results: One hundred and seven studies were examined, most of them pointing towards severalrisk factors that indicate an increased likelihood for health professionals to develop Burnout Syndrome, which has consequences on their health, quality of life, quality of health services provided, and labour and economic productivity.

Conclusion: To sum up, it is important to spread the Burnout Syndrome's signs and symptoms,and also know the major risk groups, in order to establish early screening, diagnosis and intervention strategies.

Keywords: Burnout Syndrome; Health Professionals; Prevention; Intervention

\section{Introduction}

Burnout Syndrome ${ }^{1}$ was first described by Freudenbergen in 1974 [1-3] comprising a set of non specific physical and psychological symptoms [4] resulting from overwork [5]. Later, in 2001, Maslach, Schaufeil and Leiter [6] considered it a three-dimensional occupational syndrome [7-11] characterized by Emotional Exhaustion, Depersonalization and loss of Personal Achievement at Work [1214] which would become used in most future studies. Today Burnout is a condition of physical and psychological exhaustion [15-18] resulting from chronic exposure [19-21] to work stressors [3,14,2224]. Emotional exhaustion [2,10] is the central component [25] of the syndrome and is characterized by physical and mental fatigue [24], lack of energy to complete tasks [5] and the feeling of being unable to renew energy [26]. Depersonalization $[2,10]$ refers to a painful detachment from oneself [25], in particular from one's emotions, that determines unemphatic poises and callous traits [26] and reconfiguring the attitudes in the workplace [24]. The feeling of loss of personal fulfillment [2] consists of inner experiences of incompetence [26], lower self-efficacy, and reduced job performance [23,25], as well as an overall sense of frustration [5] to professional activity.
Stress $^{2}$ and Burnout Syndrome appear in literature as health problems with increasing prevalence $[27,28]$, especially in professions that deal with persons [29] such as health professionals [13,30] police officers [25], teachers [31] and psychologists. Recently, the World Health Organization(WHO) classified it as a "state of vital exhaustion" [19], in the ICD-10 (International Statistical Classification of Diseases and Related Health Problems) and WHO pointing to Scheler's [19] vital feelings a physical/embodied experience of suffering of which the "vital sadness" associated with depression in its most severe forms is also a part.

${ }^{1}$ Burnout: state of physical and mental exhaustion determined by the exercise of a professional activity.

${ }^{2}$ Stress: a state, in which homeostasis is threatened, associated with a normal body reaction, resulting in behavioral and physiological adaptive responses to a perceived threat to re-establish the homeostasis of theorganism.

From the etiopathogenic point of view, Burnout Syndrome emerges when the work stress stimulus is disproportionate to the emotional, physical and cognitive resources of the individual [32] and results in 
reduced motivation, feelings of hopelessness and depersonalization. At presentation we find assorted emotional, cognitive, behavioural, and social symptoms [8]. Depressed mood, irritability, hostility, loss of hope, and apathy are examples of emotional symptoms [8] while cognitive symptoms [8] include changes of moral values (e.g., cynicism), disorganization, frustration, pessimism, disillusionment, loss of creativity and difficulty in concentrating. In fact, Burnout has been portrayed as a state of social isolation associated with negative thoughts and fatigue, under symptoms of anxiety and depression [11,27]. Behavioural symptoms [8] include avoidance of responsible activities (with or without absenteeism) and maladaptive behaviours such as substance abuse [33]. Finally several forms of social dysfunction [8] also emerge, such as social isolation and/or interpersonal conflicts that motivate the deterioration of family and romantic relationships, as well as avoidance of professional commitments and therefore absenteeism (medically justified).

In the particular case of Medicine there is a high risk of Burnout due to the high degree of physical, intellectual [34] and emotional strain. During undergraduate and postgraduate medical education such pressures occur with dearth of education and training in stress management [35] or in emotional intelligence. Several studies suggest that health care professionals face challenging issues $[11,36]$ such as loss of health, risk of illness, imminent death, experiencing pain [8] or uncertainty. These might lead to relational burden and thus compassion fatigue and subsequent emotional exhaustion [37], which often ends up overlapping the rewarding and pleasurable side that healthcare represents as a profession. This is particularly relevant for health professionals which have already a higher prevalence of psychological problems. They show evidence of substance abuse disorders (tobacco, alcohol, or cannabis) [7,33,38-40] depressive episodes [18,28,41-44] and anxiety, sleep and/or eating disorders $[19,45]$ as well as surging of isolated symptoms such as memory changes, attention deficit, and mood changes [46]. It seems to strike across [3,47] all medical specialties [7] and to have consequences for users [22] and for the health care system itself. In this group, perhaps as in others, there is evidence that this state may lead to other clinical cases including depressive episodes $[19,38,41,45,48]$ and suicide $[7,42,49]$ and into experiencing professional life as negative [33]. Yet there are also various negative consequences [50] to the quality of patient care [43] including the dissatisfaction of patients [51,52] poor working environment that impairs teamwork, increased medical errors $[3,5,53]$ increased post-discharge recovery time [6] increased hospital readmissions [40] more medical-legal disputes, reduced adherence to therapy [54] loss of empathy $[48,55]$ and, as above, medically justified leaves [56]. Given the possibility of suicide, some risk factors [48] such as substance abuse, untreated depression and active suicidal ideation should be taken into consideration. On a positive note, subjects may also develop protective mechanisms [20,57,58] against stressors to which they are chronically subjected in their work environment.

The repercussions of Burnout Syndrome are unquestionable and, however, there is no consensus regarding its classification since opinions diverge between a well-defined psychiatric disorder or representing the tip of the iceberg of a major depressive disorder (ICD-10 F32), a form of adjustment disorder (ICD-10 F43) or a syndrome of chronic fatigue [59]. However, to better characterize the syndrome and quantify and reckon the range of symptoms, several assessment instruments emerged, of which Maslach Burnout Inventory (MBI) [19] is the most researched. It consists of twentytwo items divided into three subscales: (1) the emotional exhaustion subscale, which assesses work exhaustion; (2) the depersonalization subscale, which assesses lack of empathy and impersonal responses; and (3) the personal accomplishment subscale, which assesses sense of accomplishment, success, and work competence. The MBI is the gold standard for assessing Burnout Syndrome and yet limited for disregarding components such as work value and loss of resources and focusing in emotional process while not estimating behavioral and cognitive aspects. Table 1 presents other instruments for Burnout Syndrome.

Despite the above mentioned facts, it remains under diagnosed [28], underreported [56,61] and undertreated [39,62] and in need of further awareness and clarification of signs and symptoms. This selective review of the literature analyses Burnout Syndrome in healthcare professions including strategies for primary prevention, clinical presentation and possible interventions also focusing in the COVID-19 pandemic stressor.

\section{Methods}

This is a selective literature review carried out on $16^{\text {th }}$ of February 2020 of articles published in the last 10 years written in Portuguese, Spanish and English. The MESH PubMed keywords used included [(Burnout Syndrome) and (Healthcare professionals)], [(Burnout Syndrome) and (Physicians)], [(Burnout Syndrome) and (Nurses)], [(Burnout) and (Prevention)], [(Burnout) and (Intervention)] and [(Medical Burnout) and (Prevention)]. Full database was assessed by two researchers ( $\mathrm{MN}$ and $\mathrm{LM}$ ) according to our inclusion criteria: language, publication date and aim of topics to be covered. Flowchart 1 presents our selection process.

\section{Discussion}

\section{Predisposing and protective factors}

Scientific evidence shows that there are modifiable and nonmodifiable factors $[3,32,63]$ that predispose to the onset of Burnout

Table 1: Other instruments for burnout syndrome.

The Copenhagen Burnout Inventory (CBI) is a nineteen-item scale that measures Burnout based on three criteria: work-related exhaustion, patient Burnout, and staff Burnout [40].

The Oldenburg Burnout Inventory (OLBI) measures Burnout in two ways: exhaustion and disconnection [54].

The Bergen Burnout Inventory (BBI) assesses exhaustion, occupational inadequacy, and cynicism about the importance of work [54].

The Physician Burnout Questionnaire (PhBQ) takes into account three main components of Burnout: exhaustion, disinterest, and loss of expectations [54].

Santinello's Italian Link Burnout Questionnaire (LBQ) considers four aspects of Burnout: psychophysical exhaustion, deterioration of relationships, feeling of professional failure, and disillusionment [28].

The Shirom-Melamed Burnout Measure (SMBM) assesses an individual's feeling of being emotionally exhausted, physically fatigued, and cognitively worn-out [60]. 

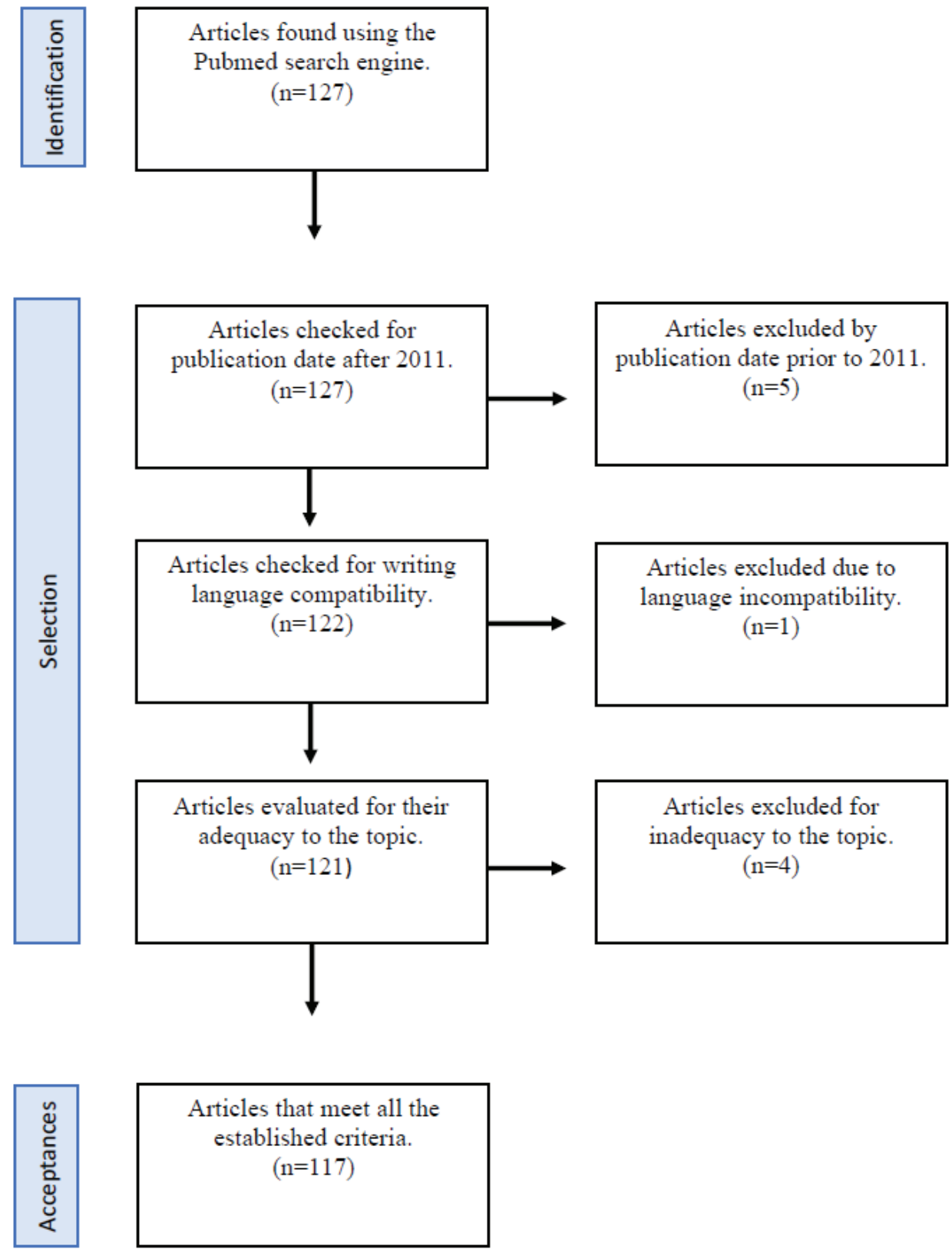

Flowchart 1: Article selection criteria.

Syndrome, as well as protective factors that make individuals more resilient. Among physicians, the risk of Burnout Syndrome depends on work, personal, psychodynamic and environmental factors [64] but the exact role of each one in the development of the syndrome is still not understood.

Most evidence suggests that health professionals aggregate several determinants to the emergence of Burnout Syndrome their profession often determines (1) sleep deprivation or fragmented sleep $[19,43,45,64,65](2)$ excessive working hours ( $>40$ hours per week) $[7,1$ $3,14,16,36,40,42,48,55,64,66,67]$ that results in a negative impact on the professional's social and personal life $[2,31,32]$ as well as (3) shift work at night, on weekends and on weekends and holidays $[27,43](4)$ struggle to balance work and personal life $[3,21,23,33,34,36,40,48](5)$ lack of support in employing institutions due to lack of human and material resources [68] lack of training in interpersonal communication, lack of employer support, insufficient remuneration $[65,69]$ and also, the hostile work environment [16,40,66,67] (6) various conflict situations $[19,31,64,66]$ such as value and interpersonal conflicts [65] (7) enduring interaction with patients and their families [13] the complexity of clinical cases $[40,65]$ the large number of patients [7] and the care of critically ill patients $[9,17,23,45,70]$ and (8) timeconsuming registration procedures including mandatory real time electronic medical records and administrative burden [14,40,66,71] which are stressors closely related to emotional exhaustion.

There are several individual risk factors [31,72] that seem to promote Burnout Syndrome, such as gender $[67,73]$ age, marital status 
$[9,69]$ length of employment contract, number of years in the career [13] and degree of career progression. With regard to gender, some authors consider that female health professionals have a higher risk of Burnout Syndrome because they have more female patients and thus tend to more frequently approach psychosocial aspects [73] which culminates in consultations with an average duration 10\% longer than consultations performed by male physicians. It should be noted, however, that other studies propose that the gender factor dissipates with age [31] so it loses relevance with increasing years of career. Thus, early career professionals [55,71,74] either less experienced [13] single $[9,26,75]$ and not yet having children 18 have a higher risk of suffering from Burnout Syndrome, compared to more experienced professionals, who have a greater sense of personal accomplishment despite a higher risk of depersonalization and emotional exhaustion. In addition, being single is associated with a lower degree of job satisfaction and greater difficulty in remaining in their jobs [75] regardless of Burnout levels.

On the other hand, there are also known protective factors, such as health work relationships [8] sense of competence and clinical autonomy, teamwork and shared task $[9,40]$ possibility of social support [21] appreciation of self-care and healthy lifestyle [21] resilience $[18,35,76]$ emotional intelligence 3 job security, and the opportunity to engage in leisure activities. Emotional resilience $[18,21,35,58,76]$ is an important asset for any professional, being defined as the ability to respond to an adverse event in a healthy and adaptive way, whether at work or at home, and is influenced by both controllable and noncontrollable factors. In the daily life of healthcare professionals, the ability to deal with adverse situations and with high pressure is crucial, because besides conferring greater resistance to Burnout Syndrome, it reduces the probability of medical error. Some personal characteristics can be promoted in order to enhance worker resilience, such as selfawareness, optimism, self-efficacy, impulse control, perseverance, emotional awareness, cognitive flexibility, and positive thinking.

${ }^{3}$ Emotional intelligence: the ability to perceive, process, and regulate emotions effectively.

\section{Specific features within medicine}

Burnout Syndrome is a cross-cutting problem in healthcare [3] that covers not only large urban hospital centers but also rural health care services [51] without discriminating age, gender, specialty, years of career, type of job, or level of pre- or post-graduate training (students, general or specialized interns). It isn't just during the medical practise, during the training itself the same factors required to achieve success (like fierce dedication to goals, continuous motivation to succeed, selfsufficiency \& self-discipline and with mediate / long-term gratification focus [77] are risk factors for Burnout. Additionally, contemporary medical culture has increased expectations by fostering prioritization of the needs of others, the need to work overtime, to expect naive avoidance of medical errors [17,77] and require continuous medical education. These unrealistic expectations often lead doctors to neglect self-care and personal well-being [17] and determine Burnout symptoms in about half of them throughout their career [47].

There are differences across medical specialties and differences might guide prevention strategies and interventions. In the so-called "stethoscope specialties" [42] pediatrics [46] stands out, particularly neonatology as areas with moderate to high prevalence of Burnout Syndrome as well as intensive care medicine, anesthesiology [5] and medical oncology. There are explanatory models for increased risk of Burnout that include for instance, for medical oncology [42] the continuous involvement with suffering of patients and their families as well as death as a daily confrontation $[23,46]$ for psychiatry
[26,77] because of aggressive patients, the risk of suicide and the range of emotional skills required for the particular pathologies and interventions [20]. In the opposite range stands physiatry allegedly for dealing with recovery and promoting resilience of individuals with disabilities [47] which may also determine a positive impact in physicians themselves (though not all evidence is consistent [47]) and cardiologists which show lower rates [78] and which protective factors have not yet been identified. The professional and personal impacts among these physicians range from anesthesiologists having higher degrees of depersonalization, shorter preoperative conversations and caring less for sharing information with patients for pain control and ensuing procedures [5] to psychiatrists who experience high levels of emotional exhaustion [20,77] and increased risk of suicide [77].

Among surgical specialties $[43,56,79,80]$ there are higher rates of Burnout syndrome (studies involving general surgery, neurosurgery, urology, vascular surgery, trauma surgery and transplant surgery) most probably representing the strain of multitask due to the assorted clinical responsibilities (out and in-patient care, emergency and surgery). There is evidence that mixed specialties such as orthopaedics and obstetrics-gynaecology present moderate levels of emotional exhaustion and depersonalization [64].

Lastly, the highest rates of Burnout occur in activities of medical triage and emergency $[42,45]$ such as in specialties as general practice $[54,67,81]$ and internal medicine emergency medicine $[7,27,74]$. The extreme prevalence $(63 \%)$ of Burnout in General practice $[54,67]$ have been explained by the proximity to users, the sense of responsibility of an entire household expectations and needs, the complexity of triage and the isolation of its everyday practice [81]. Noteworthy also is the emergency setting $[27,74]$ where the intensity, long working shifts, disturbance of the circadian rhythm and the risk of medico-legal litigation [7] determine also a higher prevalence of Burnout Syndrome.

Considering that serious medical errors [43,82] occur under Burnout Syndrome it is paramount to attend to the risk factors of individual medical specialties, particularly those at a higher risk.

\section{Consequences of burnout syndrome}

Burnout Syndrome has consequences at various levels $[1,8,13,27,41,79,83]$ namely, individual, institutional, economic, and at the level of the quality of health care provided $[7,36,38,47,61,79,84]$ so given the significant impact on the care provided, physician well-being $[29,49,70,85]$ is used as an indicator of health care quality.

Health professionals with higher levels of Burnout Syndrome present a higher percentage of medical error in clinical practice $[2,36,42,85,86]$ which compromises the quality of the service provided $[22,26,48,57,84,87]$ the level of patient satisfaction and safety $[13,23,24,43,47,67,70,83]$ as well as interpersonal relationships $[38,55,88]$. It should be mentioned as well that there is a positive correlation between Burnout levels among nurses and the mortality rate of patients [82] and nosocomial infections [66]. Besides this, health professionals also present a decrease in productivity $[13,42,66]$ and effectiveness of their work [7] which together with absenteeism $[48,56,57,72,79]$ and the increase in the number of referrals to other specialties, contribute to a negative net balance for their institutions [23,27]. Also, as discussed above, Burnout Syndrome can lead to substance use disorders, particularly, but not only, alcohol $[7,29,48,49,79,82]$ and suicidal ideation $[43,47,56,61,67,86]$ with or without suicidal behaviours [79].

Regarding mental health and illness, Burnout Syndrome has an overlap (and therefore is a confounding factor) with depressive 
episodes the relation can also be directional as Burnout can be a precipitating factor for a depressive episode [48]. It is therefore critical to make the differential diagnosis [42], as delay in diagnosing and treating a depressive episode has implications for its prognosis [42]. Depressive symptoms appear to be present early in medical training with $28 \%$ of students experiencing depressive symptoms (vs $8 \%$ of the general population) although often escaping observation either by stigma, student motivation or even the nature of the assisting role $[48,77]$. Several studies argue that, over time, Burnout Syndrome in students impairs their professionalism, clinical performance, altruism, and ethical behavior $[21,88]$ with an increased risk of depressive symptoms $[8,77]$ academic exhaustion and withdrawal, and suicidal ideation. This disorder tends to persist during medical internship and even with the passage of clinical practice [77] so continued exposure to a high level of stress culminates in neglect of self-care and reduced empathy for the patient [21] which decreases the quality of care provided.

Besides the consequences mentioned above, there were demonstrated changes from the neurobiological and imaging point of view, as Burnout Syndrome seems to determine a reduction in the volume of the grey matter of the anterior cingulate cortex, putamen and caudate, as well as changes to the functioning of the limbic system and variance on the subcortical brain volume [49].

Burnout Syndrome is also related to sleep disorders [45] which are based on chronic depletion of energy reserves, chronic activation of the hypothalamic-pituitary-adrenal axis, and increased serum cortisol concentrations [42]. Sleep deprivation, in turn, is considered a risk factor for Burnout Syndrome [45] which is associated with a state of hyper excitement and inability to relax due to worries, self-deprecation, and anxiety, triggering fatigue, mood swings, irritability, difficulty concentrating, and daytime sleepiness. It is noteworthy that adults, in general, do not sleep the recommended hours of sleep, in the case of doctors they sleep fewer hours per night than similar [45] and almost half of them attribute the reason to work schedules. Additionally, some studies argue that the continuous activation of the hypothalamicpituitary-adrenal axis is inherent to the physiopathology of both Burnout Syndrome and sleep deprivation $[42,45]$ which is associated to the appearance of physical symptoms.

As already mentioned, this syndrome is associated with health problems that transcend the realm of mental health $[13,22,41]$ since physical symptoms have been reported (e.g. myalgias [25,41] headaches $[10,19,45]$ prolonged fatigue $[19,26,57,87])$, respiratory diseases [25] cardiovascular diseases [28 41,56,87] dyslipidemia [28] overweight [28] gastrointestinal disorders [29,41,49] and appetite alterations [19].

In conclusion, Burnout Syndrome has consequences for the health professional in several ways 38 culminating in a variety of symptoms, syndromes, and negative experiences. Examples of (1) symptoms include anxiety $[13,29,57]$ mood and behavioral changes $[8,10,79]$ insomnia $[19,28,39,57,86]$ social isolation [8] (2) syndromes include depressive episodes $[7,22,28,48,49,56,87,89]$ but also (3) the most diverse experiences such as damage to interpersonal relationships $[26,29,41,43,61,79,89]$ altered value structure with calloused traits [82] and frustrated expectations.

\section{Burnout and the Covid-19 Pandemic}

Pandemics have an impact on the physical and mental health of the entire population [90] however, health professionals carry a disproportionate psychosocial burden. In the case of the Covid-19 pandemic, this has potentiated and aggravated the risk factors to which health care workers are exposed [91] namely those that constitute risk factors for Burnout Syndrome [92].

The evidence proposes that physicians are experiencing higher levels of Burnout as the pandemic [91-95] evolves, compared to preCovid-19 levels, with working on the front line being one of the few co-variables that was significantly associated with all three dimensions of Burnout. The main factors that seem to contribute to Burnout in this context are occupational factors such as the area of work, female gender [91,95] having minor children, sleep deprivation [94,95] long shifts [94] contact with suffering and death [92] witnessing the death of children and young people, lack of information, limited resources $[93,94]$ and intense workload [91]. Other factors described are the scarcity of personal protective equipment $[92,93]$ uncertainty about the final magnitude, duration, and effects of the crisis, the complexity of medical treatment for Covid-19 [94] patients, performing unusual duties, the inability to meet the patient's needs, social isolation, and the risk of contagion [90,92-94] oneself and family members or coworkers.

If emergency care doctors had evidence of higher prevalence of Burnout Syndrome they have now shown, during the Pandemic Covid-19, lower rates [91,95] compared to physicians in regular in-patient units. Tentative explanations include both that these professionals were more used to uncertainty [95] and therefore more resilient to complex decision-making or that the sense of purpose is a protective factor [91].

Although our knowledge about the effect of pandemic Covid-19 on the prevalence of Burnout Syndrome in healthcare is incipient [92] most evidence suggests that it will increase [93] and therefore it is crucial to create interventions for early intervention and to protect them (and their patients) from its adverse effects [90].

\section{Prevention and Treatment of Burnout Syndrome}

The combination of individual and organizational interventions $[2,22,44,49,61]$ have shown promising results in managing Burnout [85] and seem to emphasize the importance of early intervention $[53,64]$. Evidence suggests that individual-based interventions should promote resilience and well-being [71] while organizational interventions should focus on changing the factors that contribute to frustration and Burnout $[22,44,49,86]$. Despite external pressures, these strategies should be applied from the beginning of health professionals' careers, with the aim of developing a set of skills and personal beliefs that make them more resilient to situations that may trigger this problem $[25,53,86,96]$.

Personal interventions focus mainly on improving professional skills and promoting resilience and/or empathy [18,19,35,37,58,97,98] and are based on mindfulness ${ }^{4}$ techniques or cognitive-behavioral techniques $[2,25,83]$ aimed at promoting professional competence, improving interpersonal communication $[13,14,22,28,70]$ as well as, improving coping strategies $[8,24,62,64,71,99]$. The mechanism underlying the practice of mindfulness holds that exposure to adverse emotions, awareness of these emotions, and their observation allow the individual to better regulate and adapt to stress [100]. In addition, relaxation exercises [19,62] breathing exercises, selfawareness, reflection, control of negative emotions $[25,100]$ optimism, gratitude [98] cognitive balance and flexibility, personal development, interpersonal relationships, and communication give professionals greater adaptive capacity to stressful situations $[8,26,100,101]$.

${ }^{4}$ Mindfulness: consists of seeking full attention both to the procedural activities of each moment and to the surrounding environment. It includes a number of techniques, some of which 
are behavioral, such as lying down on the floor, walking slowly with awareness of the surrounding environment [99].

Organizational interventions aim to help health professionals recognize the early signs of Burnout Syndrome, promote health and self-care $[30,51]$ as well as restore well-being, improve decision making $[28,99]$ productivity [100] resilience $[18,54,97]$ and interpersonal communication [61]. In this regard, simple changes in schedule [2] workload reduction $[14,19]$ systematization and task division [22] promotion of professional autonomy [72] feedback mechanisms $[8,28]$ performance based pay, flexibility in working hours [51] facilitated discussion groups [19] practice of mindfulness $[40,54,71,98]$ or other more ambitious changes [83] can make a difference. Some institutions have adopted interventions based on a cognitive-behavioral approach [14] such as time management, relaxation techniques [19,25,30,42] conscious breathing [62] self-awareness training, and promotion of a healthy work environment $[28,62]$.

Also, it is important to value other problems mentioned by doctors, such as lack of time for meals, lack of access to healthy options, as well as a medical culture that despises self-care [62] which are the main obstacles to a healthy and balanced diet, fundamental for the well-being [76] and performance of health professionals. On the other hand, physical exercise $[56,62]$ as primary and secondary prevention improves quality of life, decreases anxiety, improves mood, enhances learning, memory, and creative thinking [102] and has been shown to be effective in several mental illnesses.

According to the literature, there is a benefit in searching for a differentiated professional that allows the development of coping strategies. [86] as well as the acquisition of relaxation therapies namely yoga, mindfulness and meditation [30,42] as a complement of the recovery of the health care professional, in a way that is possible to return to the work duties and, still, allowing a new psychological balance [62]. However, the resource to these tools tends to be delayed, mainly concerning the search of differentiated help, due to the devaluation of the clinic of Burnout Syndrome by peers [64] the lack of time, the fear related to the possible lack of confidentiality, due to the subjacent stigma [42] and to the possible career implications [96]. In summary, the two most important factor in the prevention of a full blown Burnout Syndrome seem to be the awareness of early signs and symptoms as well as to encouraging early intervention $[53,64]$ allowing the necessary time for recovery $[42,51]$.

\section{Conclusion}

This review of the literature shows that although the Burnout Syndrome may be in a triad, it has the most varied emotional, cognitive, behavioral and social symptoms. From a comprehensive and explanatory point of view, personal, psychodynamic, work and environmental factors that confer greater susceptibility to the emergence of Burnout were described, as well as several classification scales, currently being the Maslach Burnout Inventory (MBI) the goldstandard. It was possible to identify health professions as a risk group for Burnout Syndrome, in particular medicine where interpersonal work determines increased risk. On the particular situation of the SarsCoV-2 Pandemic, there have been verified an increasing prevalence of Burnout Syndrome with the pandemic evolution, with a few exceptions. Several studies suggest consequences in the individual and public sphere both personally and at the level of institutions that, in the context of medicine, impact both the mental health of caregivers and the quality of care they provide. Intervening in primary and secondary prevention is fundamental by knowing risk groups (e.g. specialties most affected) and establishing individual and collective awareness projects and early screening, diagnosis and intervention.

\section{Conflicts of Interest}

There are no conflicts of interest

\section{References}

1. Faizi N, Kazmi S (2017) Universal health coverage-There is more to it than meets the eye. J Fam Med Prim Care 6: 169-170.

2. De Simone S, Vargas M, Servillo G (2019) Organizational strategies to reduce physicianburnout: a systematic review and meta-analysis. Aging Clin Exp Res 33: 883-894.

3. Brown PA, Slater M, Lofters A (2019) Personality and burnout among primary carephysicians: an international study. Psychol Res Behav Manag 12: 169-177.

4. Parola V, Coelho A, Cardoso D, Sandgren A, Apóstolo J (2017) Prevalence of burnout in health professionals working in palliative care: a systematic review. JBI database System Rev Implement reports 15: 1905-1933.

5. Mumbwe MC, Mclsaac D, Jarman A, Bould MD (2020) A CrossSectional Survey to Determine the Prevalence of Burnout Syndrome Among Anesthesia Providers in Zambian Hospitals. Anesth Analg 130: 310-317.

6. Rotenstein LS, Torre M, Ramos MA, Rosales RC, Guille C, et al. (2018) Prevalence of burnout among physicians asystematic review. JAMA 320: $1131-1150$.

7. Ashooh MP, Barnette K, Moran TP, O'Shea J, Lall MD (2019) Advanced practice provider burnout in a large urban medical center. Adv Emerg Nurs J 41: 234-243.

8. Velando-Soriano A, Ortega-Campos E, Gómez-Urquiza JL, RamírezBaena L, De LaFuente El, e al. 2020) Impact of social support in preventing burnoutsyndrome in nurses: A systematic review. Japan J Nurs Sci 17: 1-10.

9. Liao RW, Yeh ML, Lin KC, Wang KY (2019) A Hierarchical Model of OccupationalBurnout in Nurses Associated With Job-Induced Stress, Self-Concept, and Work Environment. J Nurs Res 28: e79.

10. Bejer A, Domka-Jopek E, Probachta M, Lenart-Domka E, Wojnar $J$ (2019) Burnout syndrome in physiotherapists working in the Podkarpackie province in Poland. Work 64: 809-815.

11. Ashraf F, Ahmad H, Shakeel M, Aftab S, Masood A (2019) Mental health problems and psychological burnout in medical health practitioners: A study of associations and triadic comorbidity. Pakistan J Med Sci 35: 1558-1564.

12. Pulcrano M, Evans SRT, Sosin M (2016) Quality of life and burnout rates across surgicalspecialties: A systematic review. JAMA Surg 151: 970-978.

13. Zarei E, Ahmadi F, Sial MS, Hwang J, Thu PA, et al. (2019) Prevalence of burnout among primary health care staff and its predictors: A study in Iran. Int J Environ ResPublic Health 16: 2249.

14. Bernard K, McMoon M (2019) Reading between the lines for a solution to burnout. JAAPA 32: 48-50.

15. Vinnikov D, Dushpanova A, Kodasbaev A, Romanova Z, Almukhanova A, et al. (2019) Occupational burnout and lifestyle in Kazakhstan cardiologists. Arch Public Heal 77: 13.

16. Wang $H$, Jin $Y$, Wang D, Zhao S, Sang $X$, et al. (2020) Job satisfaction, burnout, and turnover intention among primary care providers in rural China: Results from structural equation modeling. BMC Fam Pract 21: 12.

17. Travers V (2020) Burnout in orthopedic surgeons. Orthop Traumatol Surg Res 106: S7-S12. 
18. Shakir HJ, Cappuzzo JM, Shallwani H, Kwasnicki A, Bullis C, et al. (2019) Relationship of Grit and Resilience to Burnout Among U.S Neurosurgery Residents. World Neurosurg 134: e224-e236.

19. Nene Y, Tadi P (2020) Definition/Introduction 2020: 8-12.

20. Rotstein S, Hudaib AR, Facey A, Kulkarni J (2019) Psychiatrist burnout: a meta-analysis of Maslach Burnout Inventory means. Australas Psychiatry 27: 249-254.

21. Bitran M, Zúñiga D, Pedrals N, et al. (2019) Burnout in students of health-care professions. Risk and protection factors. Rev Med Chil 147: 510-517.

22. Zgliczyńska M, Zgliczyński S, Ciebiera M, Kosińska-Kaczyńska K (2019) Occupational burnout syndrome in Polish physicians: A systematic review. Int J Environ Res PublicHealth 16: 5026.

23. Yates M, Samuel V (2019) Burnout in oncologists and associated factors: A systematic literature review and meta-analysis. Eur J Cancer Care (Engl) 28: e13094.

24. Harrad R, Sulla $F(2018)$ Factors associated with and impact of burnout in nursing andresidential home care workers for the elderly. Acta Biomed 89: 60-69.

25. Kalani S, Azadfallah P, Oreyzi H, Adibi P (2018) Interventions for physician burnout: Asystematic review of systematic reviews. Int J Prev Med 9: 253-263.

26. López-López IM, Gómez-Urquiza JL, Cañadas GR, De la Fuente EI, Albendín-García L, wt al. (2019) Prevalence of burnout in mental health nurses and related factors: a systematic review and metaanalysis. Int J Ment Health Nurs 28: 1032-1041.

27. Stehman CR, Testo Z, Gershaw RS, Kellogg AR (2019) Burnout, drop out, suicide: Physician loss in emergency medicine, part I. West Emerg Med 20: 485-494.

28. Kelly L (2020) Burnout, Compassion Fatigue, and Secondary Trauma in Nurses: Recognizing the Occupational Phenomenon and Personal Consequences of Caregiving. Crit Care Nurs Q 43: 73-80.

29. Rama-Maceiras $P$, Jokinen J, Kranke $P$ (2015) Stress and burnout in anaesthesia: A realworld problem? Curr Opin Anaesthesiol 28: 151158.

30. Patel RS, Bachu R, Adikey A, Malik M, Shah M (2018) Factors related to physician burnout and its consequences: A review. Behav Sci (Basel) 8: 98.

31. Hacer TY, Ali A (2020) Burnout in physicians who are exposed to workplace violence. J Forensic Leg Med 69: 101874.

32. Faria Anjos J, Heitor Dos Santos MJ, Ribeiro MT, Moreira S (2019) Connor-Davidson Resilience Scale: Validation study in a Portuguese sample. BMJ Open 9: 101874.

33. Petrelli F, Scuri S, Tanzi E, Nguyễn TTC, Grappasonni I (2019) Public health and burnout: Asurvey on lifestyle changes among workers in the healthcare sector. Acta Biomed 90: 24-30.

34. Ayyala RS, Ahmed FS, Ruzal-Shapiro C, Taylor GA (2019) Stressors contributing to burnoutamongst pediatric radiologists: results from a survey of the Society for Pediatric Radiology. Pediatr Radiol 49: 714-722.

35. Murden F, Bailey D, Mackenzie F, Oeppen RS, Brennan PA (2018) The impact and effect ofemotional resilience on performance: an overview for surgeons and other healthcare professionals. Br J Oral Maxillofac Surg 56: 786-790.

36. Garcia CDL, De Abreu LC, Ramos JLS, et al. (2019) Influence of burnout on patient safety: systematic review and meta-analysis. Medicina (Kaunas) 55: 553
37. Sturzu L, Lala A, Bisch M, Guitter M, Dobre D, et al. (2019) Empathy and Burnout-A Cross-Sectional Study Among Mental Healthcare Providers in France. J Med Life 12: 21-29.

38. Low ZX, Yeo KA, Sharma VK, Leung GK, McIntyre RS, et al. (2019) Prevalence of burnout in medical and surgical residents: A metaanalysis. Int J Environ Res Public Health 16: 1479.

39. Bragard I, Dupuis G, Fleet R (2015) Quality of work life, burnout, and stress in emergency department physicians: A qualitative review. Eur J Emerg Med 22: 227-234.

40. Patel RS, Sekhri S, Bhimanadham NN, Imran S, Hossain S (2019) A Review on Strategies to Manage Physician Burnout. Cureus 11: e4805.

41. Chemali Z, Ezzeddine FL, Gelaye B, et al. (2019) Burnout among healthcare providers in the complex environment of the Middle East: A systematic review. BMC Public Health 19: 1337.

42. Yates SW (2020) Physician Stress and Burnout. Am J Med 133: 160164.

43. Senturk JC, Melnitchouk N (2019) Surgeon Burnout: Defining, Identifying, and Addressing the New Reality. Clin Colon Rectal Surg 32: 407-414.

44. Olson K, Marchalik D, Farley H, et al. (2019) Organizational strategies to reduce physician burnout and improve professional fulfillment. Curr Probl Pediatr Adolesc Health Care 49: 100664.

45. Stewart NH, Arora VM (2019) The Impact of Sleep and Circadian Disorders on PhysicianBurnout. Chest. 156: 1022-1030.

46. Pradas-Hernández L, Ariza T, Gómez-Urquiza JL, Albendín-García L, De la Fuente El, et al. (2018) Prevalence of burnout in paediatric nurses: A systematic review and meta-analysis. PLoS One 13: e0195039.

47. Bateman EA, Viana R (2019) Burnout among specialists and trainees in physical medicine and rehabilitation: A systematic review. J Rehabil Med 51: 869-874.

48. Pospos S, Young IT, Downs N, Iglewicz A, Depp C, et al. (2018) Web-Based Tools and Mobile Applications To Mitigate Burnout, Depression, and Suicidality Among Healthcare Students and Professionals: a Systematic Review. Acad Psychiatry 42: 109-120.

49. Dubale BW, Friedman LE, Chemali Z, Denninger JW, Mehta DH, et al. (2019) Systematic review of burnout among healthcare providers in sub-Saharan Africa. BMC Public Health 19: 1247.

50. Kapu AN, Card EB, Jackson H, Kleinpell R, Kendall J, et al. (2019) Assessing and addressing practitioner burnout: Results from an advanced practice registered nurse health and well-being study. J Am Assoc Nurse Pract 33: 38-48.

51. Marquez-Cunningham D, Lenherr E, Flynn E, Warner J, Zackula R, et al. (2019) Physician Burnout in a Rural Kansas Community. Kansas J Med 12: 109-116.

52. Al Ma'mari Q, Sharour LA, Al Omari O (2020) Fatigue, burnout, work environment,workload and perceived patient safety culture among critical care nurses. Br J Nurs 29: 28-34.

53. Bilal H, Sari HY (2020) Relationship between burnout and patient safety attitudes inpediatric nurses in a hospital in Turkey. Enferm Clin 30: $37-41$

54. Minichiello V, Hayer S, Gillespie B, Goss M, Barrett B (2020) Developing a mindfulness skills-based training program for resident physicians. Fam Med 52: 48-52. 
55. Ferreira S, Afonso P, Ramos MDR (2020) Empathy and burnout: A multicentre comparative study between residents and specialists. Eval Clin Pract 26: 216-222.

56. Robinson DBT, James OP, Hopkins L, Brown C, Bowman C, et al. (2020) Stress and Burnout in Training; Requiem for the Surgical Dream. J Surg Educ. 77: e1-e8.

57. Papaefstathiou E, Tsounis A, Malliarou M, Sarafis P (2019) Translation and validation of thecopenhagen burnout inventory amongst greek doctors. Heal Psychol Res 7: 15-20.

58. Lall MD, Gaeta TJ, Chung AS, Chinai SA, Garg M, et al. (2019) Assessment of physician well-being, part two: Beyond burnout. West J Emerg Med 20: 291-304.

59. Jahangard L, Hedayati $M$, Abbasalipourkabir $R$, Haghighi $M$, Ahmadpanah $M$, et al. (2019) Omega-3-polyunsatured fatty acids (O3PUFAs), compared to placebo, reduced symptoms of occupational burnout and lowered morning cortisol secretion. Psycho neuro endocrinology 109: 104384.

60. Schilling R, Colledge F, Brand S, Ludyga S, Gerber M (2019) Psychometric Properties and Convergent Validity of the ShiromMelamed Burnout Measure in Two German-Speaking Samples of Adult Workers and Police Officers. Front Psychiatry 101-12.

61. Lacy BE, Chan JL (2018) Physician Burnout: The Hidden Health Care Crisis. ClinGastroenterol Hepatol. 16: 311-317.

62. Slavin S (2019) Preventing physician burnout: Satisfaction or something more? Isr J HealthPolicy Res 8: 10-12.

63. Durham ME, Bush PW, Ball AM (2018) Evidence of burnout in healthsystem pharmacists. Am J Heal Pharm 75: S93-S100.

64. Smith RP (2019) Burnout in obstetricians and gynecologists. Clin Obstet Gynecol 62: 405-412.

65. Busireddy KR, Miller JA, Ellison K, Ren V, Qayyum R, et al. (2017) Efficacy of Interventions to Reduce Resident Physician Burnout: A Systematic Review. J Grad Med Educ 9: 294-301.

66. Dyrbye LN, Shanafelt TD, Johnson PO, Johnson LA, Satele D, et al. (2019) A cross-sectional study exploring the relationship between burnout, absenteeism, and job performance among American nurses. BMC Nurs 18: 1-8.

67. Creager J, Coutinho AJ, Peterson LE (2019) Associations Between Burnout and Practice Organization in Family Physicians. Ann Fam Med 17: 502-509.

68. Barnes EL, Ketwaroo GA, Shields HM (2019) Scope of Burnout Among Young Gastroenterologists and Practical Solutions from Gastroenterology and Other Disciplines. Dig Dis Sci 64: 302-306.

69. Lee CY, Wu JH, Du JK (2019) Work stress and occupational burnout among dental staff in a medical center. J Dent Sci 14: 295-301.

70. Hamdan AB, Alshammary S, Javison S, Tamani J, AlHarbi M (2019) Burnout Among Healthcare Providers in a Comprehensive Cancer Center in Saudi Arabia. Cureus 11:1-14

71. Walsh AL, Lehmann S, Zabinski J, Truskey M, Purvis T, et al. (2019) Interventions to Prevent and Reduce BurnoutAmong Undergraduate and Graduate Medical Education Trainees: a Systematic Review. Acad Psychiatry 43: 386-395.

72. O'Connor K, Neff DM, Pitman S (2018) Burnout in mental health professionals: A systematic review and meta-analysis of prevalence and determinants. Eur Psychiatry 53: 74-99.

73. Linzer M, Harwood E (2018) Gendered Expectations: Do They Contribute to High BurnoutAmong Female Physicians? J Gen Intern Med 33: 963-965.
74. Kansoun Z, Boyer L, Hodgkinson M, Villes V, Lançon C, et al. (2019) Burnout in French physicians: A systematic review and metaanalysis. J Affect Disord 246: 132-147.

75. Rao S, Ferris TG, Hidrue MK, Lehrhoff SR, Lenz S, et al. (2020) Physician Burnout, Engagement and Career Satisfaction in a Large Academic Medical Practice. Clin Med Res 18: 1-20.

76. Heitor MJ, Dinis A, Sousa L, Moreira S, Carreiras J et al. (2021) Psychosocial Determinants of Presenteeism at the Workplace in the Pre-COVID-19 Era in A Southern European Country-The Mediating Role of Mental Health and Wellbeing. J Psychiatry Behav Sci 4: 1056

77. McFarland DC, Hlubocky F, Riba M (2019) Update on Addressing Mental Health and Burnout in Physicians: What Is the Role for Psychiatry? Curr Psychiatry Rep 21: 108.

78. Mehta LS, Lewis SJ, Duvernoy CS, Rzeszut AK, Walsh MN, et al. (2019) Burnout and Career Satisfaction Among U.S.Cardiologists. J Am Coll Cardiol 73: 3345-3348.

79. Maxson, Mitchell (2016) 乳鼠心肌提取 HHS Public Access. Physiol Behav.176: 139-148.

80. Dahmash $A B$, Alhadlaq AS, Alhujayri AK, Alkholaiwi F, Alosaimi NA (2019) Emotional Intelligence and Burnout in Plastic Surgery Residents. Plast Reconstr Surg Glob Open 7: e2057.

81. Bugaj TJ, Valentini J, Miksch A, Schwill S (2020) Work strain and burnout risk in postgraduate trainees in general practice: an overview. Postgrad Med 132: 7-16.

82. Reith TP (2018) Burnout in United States Healthcare Professionals: A Narrative Review. Cureus 10: e3681.

83. Panagioti $M$, Panagopoulou $E$, Bower $P$, Lewith $G$, Kontopantelis $E$, et al. (2017) Controlled interventions to reduce burnout in physicians a systematic review and meta-analysis. JAMA Intern Med 177: 195205

84. West CP, Dyrbye LN, Erwin PJ, Shanafelt TD (2016) Interventions to prevent and reduce physician burnout: a systematic review and meta-analysis. Lancet 388: 2272-2281.

85. Romani M, Ashkar K (2014) The core institutions of representative government like parties, parliaments, and executives in many established democracies, as argued elsewhere, it appears that this process has not yet undermined the public's confidence in the Unitedfvations. 33. Libyan J Med 9: 23556-23562.

86. Axisa C, Nash L, Kelly P, Willcock S (2019) Psychiatric morbidity, burnout and distress in Australian physician trainees. Aust Heal Rev 44: 31-38.

87. Otto MCB, Hoefsmit N, van Ruysseveldt J, van Dam K (2019) Exploring proactive behaviorsof employees in the prevention of burnout. Int $J$ Environ Res Public Health 16: 3849.

88. Dyrbye $L N$, West $C P$, Hunderfund AL, Sinsky CA, Trockel M, et al. (2019) Relationship Between Burnout, Professional Behaviors, and Cost-Conscious Attitudes Among US Physicians. J Genlntern Med 35: 1465-1476.

89. Hyochol Ahn, Michael Weaver, Debra Lyon, Eunyoung Choi RN, Roger B, et al. (2017) 乳鼠心肌提取 HHS Public Access. Physiol Behav 176:139-148.

90. Batra K, Singh TP, Sharma M, Batra R, Schvaneveldt N (2020) Investigating the psychological impact of COVID-19 among healthcare workers: A meta-analysis. Int J Environ Res Public Health 17: 9096

91. Amanullah S, Shankar RR (2020) The Impact of COVID-19 on Physician Burnout Globally: A Review. Healthcare 8: 421. 
92. Duarte I, Teixeira A, Castro L, Marina S, Ribeiro C, et al. (2020) Burnout among Portuguese healthcare workers during the COVID-19 pandemic. BMC Public Health 20:1-10.

93. Albott CS, Wozniak JR, McGlinch BP, Wall MH, Gold BS, et al. (2020) Battle Buddies: Rapid Deployment of a Psychological Resilience Intervention for HealthCare Workers during the COVID-19 Pandemic. Anesth Analg 131: 43-54.

94. Raudenská J, Steinerová V, Javůrková A, Urits I, Kaye AD, et al. (2020) Occupational burnout syndrome andpost-traumatic stress among healthcare professionals during the novel coronavirus disease 2019 (COVID-19) pandemic. Best Pract Res Clin Anaesthesiol 34: 553-560.

95. Shreffler J, Petrey J, Huecker M (2020) The impact of COVID-19 on healthcare workerwellness: A scoping review. West J Emerg Med 21: 1059-1066.

96. Gazelle G, Liebschutz JM, Riess H (2015) Physician Burnout: Coaching a Way Out. J GenIntern Med 30: 508-513.

97. Moorfield C, Cope V (2020) Interventions to increase resilience in physicians: A structured literature review. Explore 16: 103-109.
98. Guo YF, Lam L, Plummer V, Cross W, Zhang JP (2020) A WeChatBased "Three Good Things" Positive Psychotherapy for the Improvement of Job Performance and Self-efficacy in Nurses with Burnout symptoms: A Randomized Controlled Trial. J Nurs Manag 28: 480-487.

99. Janssen M, Heerkens Y, Kuijer W, Van der Heijden B, Engels J (2018) Effects of Mindfulness-Based Stress Reduction on employees' mental health: A systematic review. PLoS One 13: e0191332.

100. Suleiman-Martos N, Gomez-Urquiza JL, Aguayo-Estremera R, Cañadas-De La FuenteGA, De La Fuente-Solana El, et al. (2020) The effect of mindfulness training on burnout syndrome in nursing: $A$ systematic review and meta-analysis. J Adv Nurs 76: 1124-1140.

101. Jeung DY, Kim C, Chang SJ (2018) Emotional labor and burnout: A review of the literature. Yonsei Med J 59: 187-193.

102. Malm C, Jakobsson J, Isaksson A (2019) Physical Activity and SportsReal Health Benefits: A Review with Insight into the Public Health of Sweden. Sports 7: 127. 